2016-09-29

The use of team-based learning in a second year undergraduate pre-registration nursing course on evidence-informed decision making

\title{
Morris, JM
}

http://hdl.handle.net/10026.1/5501

10.1016/j.nepr.2016.09.005

Nurse Education in Practice

All content in PEARL is protected by copyright law. Author manuscripts are made available in accordance with publisher policies. Please cite only the published version using the details provided on the item record or document. In the absence of an open licence (e.g. Creative Commons), permissions for further reuse of content should be sought from the publisher or author. 
THE USE OF TEAM-BASED LEARNING IN A SECOND YEAR UNDERGRADUATE PREREGISTRATION NURSING COURSE ON EVIDENCE-INFORMED DECISION MAKING

Dr Jenny Morris, PhD, RN.

Associate Professor (Senior Lecturer), School of Nursing and Midwifery, Faculty of

Health \& Human Sciences, Plymouth University, Knowledge Spa, Treliske, Truro, England TR1 3HD.

Correspondence: Dr Jenny Morris (jenny.morris@plymouth.ac.uk); telephone: 0044 1872256461. 


\section{ABSTRACT}

More engaging teaching and learning strategies are needed to teach research-related courses to pre-registration nursing students. Team-based learning was implemented within a second year pre-registration nursing evidence-informed decision making course. Results from a questionnaire survey indicated that $70 \%$ believed team-based learning was appropriate for the course, $60 \%$ that it was an effective and motivating learning strategy, and $54 \%$ recommended using team-based learning in other courses. The results from ten student interviews illustrated the positive way in which team-based learning was perceived, and how the students thought it contributed to their learning. Test results were improved with an increase in the numbers of students achieving $70 \%$ or higher; and higher scores for students in the lowest quartile. Team-based learning was shown to be an effective strategy that preserved the benefits of small group teaching with large student groups.

Highlights:

Team-based learning is an effective strategy to engage large groups of students and develop team-working.

$>$ Team-based learning ensures student accountability for their learning.

> Student results were improved in an evidence-informed decision making course using team-based learning when compared with a historical cohort.

> Peer-to-peer learning is effectively demonstrated with team-based learning.

Keywords: Team-based learning, Pre-registration students, Nursing. 


\section{INTRODUCTION}

Within pre-registration nursing curricula across the past 20 years there has been a change in emphasis in how research-based subjects are taught with a shift in focus from enabling students to 'do' research to using research-based evidence in practice. This is the result of increasing knowledge about how high quality research evidence can help ensure the provision of cost-effective health care, and a consequent requirement for health care professionals to deliver evidence-based practice (e.g. Stevens 2013). Whilst the term 'evidence-based practice' is still commonly used, in recent years there has been a change in terminology from 'evidence-based practice' to 'evidence-informed decision making'. This emphasises that research-based evidence 'informs' decision making alongside clinical expertise, available resources and patient values, rather than being the sole basis for practice as implied by the term 'evidence-based practice' (Nevo and Slonim-Nevo 2011, Canadian Nurses Association 2010). This is the term adopted within our curriculum and will be used throughout this paper. Whilst, it is expected that evidence-informed decision making is included in pre-registration nursing curricula (Ciliska 2005; Nursing \& Midwifery Council 2010; Emanuel et al, 2011), the challenge is how best to teach the subject in a way that motivates and engages students, especially with large student cohorts. Whilst blended learning has been advocated with a mix of lectures and small workshops (e.g. Johnson et al, 2010), this approach is resource intensive with large groups of students. There is a need to identify a strategy that can maximize both independent, peer learning and team working when students are 'oncampus', and also enable off-campus independent study.

One strategy to consider is team-based learning which was developed as a method of ensuring the benefits of small group teaching with large groups of $200+$ students (Michaelsen, 2002). As a strategy, team-based learning is consistent with the principles of constructivist learning theory (Hrynchak and Batty 2012) with an 
emphasis on academic facilitation using dialectical questioning. The strategy follows a precise sequence of activities: (i) out-of-class preparation whereupon students are given resources to study with clear objectives to direct their learning; (ii) the 'readiness assurance process' that consists of individual and team multiple choice question tests designed to provide immediate feedback; (iii) team application activities in which teams work on problems relevant to an applied context; and (iv) peer feedback (Parmelee and Michaelsen, 2010; Parmelee et al 2012). The first part of the sequence is similar to the flipped classroom in that students engage in pre-learning activities. With team-based learning, however, there is a formalised structure for developing student learning beyond the pre-learning, and the work is done in permanent teams of 5-7 students formed in advance by the academic team to ensure team diversity (Balan et al 2015; Ratta 2015). With flipped classroom, the only constant is that students engage in directed pre-class learning but the nature of the pre-class learning and the teaching structures that follow will differ between courses. This heterogeneity in approach might explain why results are mixed regarding the use of the flipped classroom (Betihavas et al 2016). As health care professional programmes have become more competency based, it is also of increasing importance to explore teaching and learning strategies such as team-based learning that are active, learner-centred strategies that can foster the development of communication and problem-solving skills, help promote effective team working as well as ensure that deep rather than superficial learning takes place (Sibley and Parmelee, 2008).

Team-based learning is increasingly used in health care curricula, especially medicine and pharmacy but to date has been used mainly in the United States. Evaluation research has provided important insight into some of the benefits of using team-based learning. For example, studies of first year (Nieder et al, 2005), second year (Hunt et al, 2003; Koles et al, 2005), third year (Levine et al, 2004) and 
fourth year medical students (Zgheib et al, 2011) demonstrated higher levels of student engagement when compared with previous teaching methods such as lecture-based courses. Research has also shown that exam results were higher for students using team-based learning, that a higher percentage of $A$ grades were achieved $(23 \%$ compared with $9.5 \%$ for non-team-based learning courses), and that no students using team-based learning failed the exam (Letassy et al, 2008). Additionally, students in the lowest academic quartile demonstrated better exam results when using team-based learning compared with other strategies (Koles et al, 2005; Chung et al, 2009; Tan et al, 2011). Improvements in critical thinking and problem solving have also been reported when using team-based learning (Deardorff et al. 2010).

Previous teaching strategies for evidence-informed decision making in our curriculum have included didactic lectures, interactive webinars supported by group seminars and directed study. Our experience was that the majority of students did not prepare for or engage during facilitated sessions, did not read widely around the subject and generally only undertook focused study at the end of the course to prepare for the summative assessment. This resulted in a superficial level of learning with the consequence that many students were not prepared for the third year evidence-informed decision making course.

During a sabbatical on how best to teach evidence-informed decision making the course leader experienced team-based learning. This experience, together with a requirement to revalidate the curriculum to prepare for nursing becoming a graduatebased profession (Nursing and Midwifery Council 2010); plus a significant increase in our student numbers, led to the decision to implement team-based learning in the second year pre-registration evidence-informed decision making course. The aim of this paper is to report on the evaluation of this first implementation from the perspective of the students. 


\section{METHODS}

\section{Design}

The strongest design would have been a randomised controlled trial. This was not practically possible due to a lack of the resources necessary to run the course with two different student groups; nor desirable because it was already known that the 'standard' approach had not facilitated student engagement nor resulted in students undertaking the necessary preparatory work prior to facilitated sessions. Consequently, a postintervention evaluation was used that included three distinct elements to add robustness to the design: (i) a cross-sectional questionnaire survey, (ii) structured interviews with a convenience sample of 10 students; and (iii) student test results.

\section{Sample}

All second year pre-registration BSc Nursing students enrolled on the evidenceinformed decision making course at a University in England were invited to take part in the end of course evaluation $(n=257)$. This required all participating students to complete a questionnaire on the last day of the course, and for a convenience sample of 10 students to be interviewed at a later date. Students were asked to indicate on the consent form if they were willing to be interviewed. The aim was to interview 10 students to include two students from each nursing field (adult, child and mental health).

\section{Ethics}

Approval for the study was granted by the University Faculty Ethics Committee. 


\section{Data Collection}

A 50 item questionnaire was developed for the student survey. This consisted of a validated perception of team-based learning and teamwork scale (Vasan et al, 2009), and a validated team performance scale (Thompson et al, 2009). Additional questions were developed specifically for the study: eight questions that related to the organisation of the course and overall experience of team-based learning, and six questions about the students' profile. A copy of the questionnaire is available on request. The survey data was collected on the last day of the course in January 2013.

A structured interview schedule was developed that contained 17 questions about the team-based learning activity sequence. All interviews were undertaken by a research assistant employed for the study, were digitally recorded and took place on the University campus between February and March, 2013.

\section{Data Analysis}

(i) The questionnaire data were analysed using SPSS version 20 for Windows. The focus of the analysis was on the students' perception of team-based learning and team working. (ii) The structured questions provided the framework for analysis of the interview data which were summarised by the research assistant to group quotes from each participant for each of the questions asked. Similarities and differences between the data were explored, and verbatim quotes used to illustrate their views ensuring representation of all views. (iii) The overall pass rate for the summative assessment was compared to the results from the examination undertaken by the students in the year prior to the team-based learning implementation. 


\section{Team-Based Learning Process}

The second year evidence-informed decision making course was divided into four units and was scheduled over 13 days between the end of October 2012 and the end of January 2013. Each of the four facilitated unit sessions ran for three hours and were scheduled at approximately fortnightly intervals. The individual and team tests took approximately one hour, as did the application activities and this timeframe was informed by the experience of others (Nieder et al, 2005; Letassy et al, 2008; Banfield et al, 2012). The readiness assurance tests consisted of 12 or 15 multiple choice questions, each of which had four response options only one of which was correct. To reward partial knowledge students could allocate a maximum of four points across the four response options which enabled them to demonstrate confidence in their knowledge (Sweet and Michaelsen, 2012). IF-AT (immediate feedback assessment technique) cards were used for the team tests which has been shown to benefit learning as students get immediate feedback on their test performance (bttp://www.epsteineducation.com/home/about/uses.aspx; (Epstein and Brosvic, 2002). The $4 \mathrm{~S}$ structure was used for the application activities: significant problem, same problem, specific choice and simultaneous reporting (Pelley and McMahon, 2008; Sweet and Michaelsen, 2012). There were two problems for each of the four application activities.

\section{Team Size and Formation}

The total number of students was 257 . The students were divided into five groups each of which was facilitated by two academics. Forty-four teams of 5-7 students were formed that ensured a balance of nursing field, age and gender across the teams. 


\section{RESULTS}

\section{(i) Survey Results}

Two hundred and fifty-seven students completed the evidence-informed decision making course; and completed evaluation questionnaires were received from 196 (76\%). The sample characteristics were representative of our nursing programmes: $62 \%$ were from the adult field, $25 \%$ mental health and $13 \%$ child. Eighty-eight percent were female; $54 \%$ aged $18-25$ years, $28 \% 26-35$ years, and $18 \%$ were aged 35 years or over.

\section{Course Organisation}

Five questions related specifically to the organisation of the course using team-based learning. The results showed that $58 \%$ strongly agreed/agreed that the team-based learning approach was appropriate for the course (25\% were uncertain); $46 \%$ strongly agreed/agreed that the preparatory information provided during the induction week at the start of the year and in the course handbook prepared them for what to expect ( $21 \%$ were uncertain); $77 \%$ strongly agreed/agreed that the division of the course into four units worked well (11\% were uncertain), and $62 \%$ strongly agreed/agreed that the tutors facilitated the sessions well (21\% were uncertain).

\section{Perceptions of Team-Based Learning}

The questionnaire consisted of two subscales each of which consisted of seven items. Each item score ranged from -2 to +2 with a maximum subscale score of 14 . Cronbach's alpha was 0.81 for the perception of team-based learning subscale; and 0.72 for the perception of teamwork subscale. The summary results from each subscale are shown in Table 1 from which it can be seen that the mean score for the perception of teamwork 
subscale was significantly higher than that for the perception of team-based learning subscale $(t=18.13, d f=183, p<0.0001)$.

(Table 1 here)

Responses to additional questions about team-based learning not included in the subscales are shown in Table 2. Whilst $40 \%$ indicated they learned better from lecturer presentations than in team work, over $50 \%$ of the students considered teambased learning to be an appropriate approach for the course, that it was an effective and motivating learning strategy, and they would recommend using team-based learning in future courses. The perceived usefulness of the individual tests as useful learning activities was mixed. It should also be noted that many students were uncertain which is consistent with the findings reported earlier.

(Table 2 here)

\section{Perceptions of Team Performance}

One hundred and eighty-six students completed the Team Performance Scale and the results showed that the students rated their teams as performing well with a mean score of $99.68,95 \% \mathrm{Cl} 98.01,101.34$ (maximum score possible of 108). The scale had high internal consistency with a Cronbach's alpha of 0.94 . The scale results were comparable to those reported by Thompson et al (2009) who reported an overall mean scale score of $96.0(\mathrm{SD}=14)$.

\section{(ii) Results from Interviews}

Fifteen students agreed to be interviewed and 10 were purposively selected by the research assistant. The aim had been to include at least two students from each nursing field but only one student volunteered from the child nursing cohort. The final sample was seven adult field students, one child field student and the two mental health field students who volunteered. The findings from the interviews were grouped according 
to the sequence of activities used throughout the team-based learning process as reported below.

First Day of the Course: Practice Day

In order to prepare students for the team-based learning approach, the first day of the course was designed to enable the students to experience the team-based learning sequence of activities in an informal way, and to meet their team members. The practice session clarified for the students in a practical way how the team-based learning process worked, how the academic team facilitated sessions, and what they needed to do to help ensure success: Int 3: It allowed me to put strategies in place to deal with things If we went straight into the tests I couldn't have done that.

Int 9: It gave one inside knowledge. It helped us to understand the structure. It gave us the opportunity to meet our team, find out who everybody was and make connections.

Accessing and Using Resources for the Preparatory Work

The clear objectives and direction provided on the web-based resources were appreciated by students:

Int. 3: I really liked the self-learning. I really liked the way we were given the resources and we knew exactly which resources to read and we could go away in our own time and read them.

All students interviewed had managed to access and read the majority of the resources. The resources were varied including podcasts, PowerPoint presentations and readings; and this variety and choice was appreciated by many: 
Int. 5: I thought the information collected together for the students was fantastic. The visual and audio and presentation there was such a good variety that it was very good for someone like me who is dyslexic.

Some students, however, stated that there was too much to study and complained about duplicated information; and some students misunderstood the purpose of the study believing they had to memorise all the information in all the resources rather than developing knowledge around the subject concepts:

Int. 7: I felt I had to memorise them as I did not know what would be in the tests and I felt I might miss the relevant sentence.

\section{Readiness Assurance Tests}

The students believed that the tests provided an incentive to undertake the independent study, and that the process required all team members to study the same resources to make an active contribution to the team:

Int. 2: It made me more focused; there was no 'drift' possible, because you had to focus for each test. Also the tests were not too long, so were not overwhelming. Int. 6: They should use it more as people have to pull their weight and cannot hide behind others and say 'Ifound that too'. Having read nothing!

When asked about the team tests the students were enthusiastic about how this aspect of the process contributed to their learning, especially the peer-to-peer discussion:

Int. I: Team tests were the best thing, it was good to discuss topics. Team members telling each other things if they were not understood by some of the team.

Int. 2: Really enjoyable. I normally work alone but working towards a mark with a team was good. The team mark was better than the individual so it paid to work together. 
Int. 9: The whole process of listening to others and giving your own feedback and your own ideas about what things meant, and either being backed up by others saying 'I'm not sure that is quite right you know; this is my perspective on it'...It really did help me to understand some concepts. You know there were some things I really had not grasped and didn't realise that until the team based tests...I came away you know thinking 'now I get it'.

\section{Application Activities}

The purpose of the application activities was to provide students with an opportunity to apply the concepts learned to a problem relevant to evidence-informed decision making. The benefit of this was evident from some of the views expressed:

Int. 2: You do learn from other people so being given an active way to do that made sure you were on the right track.

Int. 4: They were very useful and I have used my knowledge since.

Some students did not find the application activities useful, and the fact they were ungraded contributed to a perceived lack of effort made by some students:

Int. 5: Did not work at all. After individual and group tests everyone had had enough. It did open discussion but it was at the end of the session and people were fatigued. Also there was no score for it - so people were just not interested.

Int. 9: Mixed views on that really. .Some of the things helped me cement what I had learnt.... So although some people in the team couldn't be bothered, I was quite keen to do them as I found them helpful. 


\section{(iii) Test Results}

The summative assessment was the four unit tests, weighted so that individual tests contributed $70 \%$ of the overall mark. The overall pass rate for the course at first attempt was $89 \%$ (10\% higher than the results for the evidence-informed decision making course for the previous year); and $20 \%$ scored over $70 \%$ and a further $39 \%$ between 60 $69 \%$. What was of most interest, however, was the change in scores between the lowest quartile for the two courses. The lowest quartile was $56 \%$ for the team-based learning course (median 62\%), compared with $40 \%$ for the non-team-based learning course (median 50\%) undertaken in the previous year. Clearly it is not possible to draw a firm conclusion from this result as the methods of assessment were different: the team-based learning assessment was on-going throughout the course and consisted of an individual and team element, whereas the exam for the non-team-based learning course was held six weeks following the last day of the course. The mean was $52.64 \%$ for the individual tests, and $82.67 \%$ for the team tests which indicates the benefit of team working and peer learning.

\section{DISCUSSION}

This was the first time that team-based learning was used in the BSc Nursing programme, and indeed within any programme in the wider University. Introduction of the strategy represented a radical departure from teaching methods used previously because of the emphasis on out-of-class preparation and the readiness assurance process which formed the summative assessment.

The pass rate of $89 \%$ at first attempt together with an overall increased percentage of students obtaining marks in the higher mark bands, plus the relatively positive evaluation demonstrates the effectiveness of team-based learning as reported by others (Koles et al, 2005). The finding that the team results were higher than the 
individual results was consistent with results published els ewhere and reflects the benefits of team learning (e.g. Chung et al, 2009).

Part of the success of team-based learning is due to the out-of-class preparatory work which students have to undertake to ensure they have acquired the knowledge necessary to successfully complete the tests and participate in the application activities. It was evident from the student interviews that students wanted to do well for themselves, and also did not want to let their team members down (Hunt et al, 2003). Itwas clear that significant learning took place as a consequence of the readiness assurance process. The students were appropriately challenged by the test questions and particularly liked the scoring method in which they were rewarded for partial knowledge. It was evident from the interviews that substantial learning took place during the team tests with a high level of engagement and discussion and evidence of students helping each other (Banfield et al, 2012).

It was also evident from the interview data, that there were elements of teambased learning that some students did not like. For some there were too many resources to study even though the variety and access was appreciated. This was linked to the fact that some students had clearly misunderstood how to use the resources and were trying to memorise the information rather than gain an understanding of subject concepts. A second issue was around the value of the ungraded application activities. This has also been reported in the literature, and a recent review highlighted that grading or ungrading application activities did not influence overall student performance but graded activities clearly added to students' anxiety levels (Deardorff et al. 2014). These more negative perceptions of team-based learning emphasise the importance of ensuring students are well prepared for the requirements of team-based learning, and in particular how to use the study resources. 
This was the first implementation of team-based learning and the survey result that some students did not enjoy the team-based learning approach, and felt that they learned better from lecture presentations is not surprising. This was the first time that team-based learning had been introduced into the curriculum, it was implemented in a second year course and consequently students were used to more didactic/lecturer led methods of delivery and being 'given' information. Many students, however, were 'undecided' in their perceptions of team-based learning. The interview data suggested that some students felt there were too many resources to study and this too will have influenced overall perceptions as this was the first course in which they had to undertake all the recommended reading. As completion of the preparatory work was essential to succeed in the tests, especially the individual tests, this might explain why some students indicated the individual tests were not useful learning activities. Only $16 \%$ disagreed/strongly disagreed with the statement that team-based learning should be used in other courses, and 54\% agreed/strongly agreed indicating that the benefits of team-based learning were also acknowledged.

The design utilised in this study was a post-intervention evaluation as it was not practical to consider a randomised controlled trial both because of the logistics in identifying a large enough teaching team that could deliver the course using teambased learning and non-team-based learning strategies; and because of the known limitations of the 'standard' approach. To enhance the rigour of the post-intervention design, data were collected from three sources that involved use of a reliable and valid questionnaire for the survey, and a research assistant to undertake the interview to ensure that participants gave their opinions freely.

\section{CONCLUSIONS AND RECOMMENDATIONS}


In conclusion, this first implementation of team-based learning was a success. The student results were good with both top performing and weaker students showing improvement over an historical cohort. Whilst the data from the survey and interviews revealed positive and negative perceptions, the benefits of team-based learning in fostering deep learning around subject concepts, and enhancing team working were highlighted. This is important in the context of teaching subjects such as evidenceinformed decision making where the difficulties of engaging students are known, as well as developing the team working skills essential for professional development.

The results obtained from this study are consistent with the existing evaluation literature. Others wanting to implement team-based learning are likely to experience the added value that we observed using this teaching and learning strategy with large groups of students; and it is a strategy that can be used with any academic subject. At a time when nursing education is under pressure with increased student numbers it is timely to review teaching strategies and to perhaps make better use of strategies that not only develop a deep understanding of core concepts, but also foster high level team working skills.

Conflict of Interest: None 


\section{REFERENCES}

Balan, P., Clark, M., Restall, G. 2015. Preparing students for flipped or team-based learning methods. Education and Training 57(6), 639-657.

Banfield, V., Fagan, B., Janes, C. 2012. Charting a new course in knowledge: Creating life-long critical care thinkers. Dynamics 23(1), 24-28.

Betihavas, V., Bridgman, H., Kornhaber, R., Cross, M. 2016. The evidence for 'flipping out'. A systematic review of the flipped classroom in nursing education. Nurse Education Today 38, 15-21.

Canadian Nurses Association. Position Statement: Evidence-Informed Decision-Making and Nursing Practice. 2010. https://www.cna-aiic.ca/en/advocacy/policy-supporttools/cna-position-statements

Chung, E.-K., Rhee, J.-A., Baik, Y.-H., Oh-Sun, A. 2009. The effect of team-based learning in medical ethics education. Medical Teacher 31, 1013-1017.

Ciliska, D. 2005. Educating for evidence-based practice. Journal of Professional Nursing 21(6), 345-350.

Deardorff, A., Moore, J., Borges, N., Parmelee, D. 2010. Assessing first year medical student attitudes of effectiveness of team-based learning. Journal of the International Association of Medical Science Educators 20(2), 67-71.

Deardorff, A., Moore, J., McCormick, C., Koles, P., Borges, N. 2014. Incentive structure in team-based learning: Graded versus ungraded group application activities. Journal of Educational Evaluation for Health Professionals 11(6), 1-7.

Emanuel, V., Day, K., Diegnan, L., Pryce-Miller, M. 2011. Developing evidence-based practice among student. Nursing Times 107(49/50), 21-23.

Epstein, M., Brosvic, G. 2002. Students prefer the immediate feedback assessment technique. Psychological Reports 90, 1136-1138. 
Hrynchak, P., Batty, H. 2012. The educational theory basis of team-based learning. Medical Teacher 34, 796-801.

Hunt, D., Haidet, P., Coverdale, J., Richards, B. 2003. The effect of using team learning in an evidence-based medicine course for medical students. Teaching and Learning in Medicine 15(2), 131-139.

Johnson, N., List-Ivankovic, J., Eboh, W., Ireland, J., Adams, D., Mowatt, E., Martindale, S. 2010. Research and evidence-based practice: Using a blended approach to teaching and learning in undergraduate nurse education. Nurse Education in Practice 10, 43-47. Koles, P., Nelson, S., Stolfi, A., Parmelee, D. DeStephen, D. 2005. Active learning in a year 2 pathology curriculum. Medical Education 39, 1045-1055.

Letassy, N., Fugate, S., Medina, M., Stroup, J., Britton, M. 2008. Using team-based learning in an endocrine course taught across two campuses. American Journal of Pharmaceutical Education 72(5), 1-6.

Levine, R., O'Boyle, M., Haidet, P. et al 2004. Transforming a clinical clerkship with team learning. Teaching and Learning in Medicine 16(3), 270-275.

Michaelsen, L. 2002. Getting started with team-based learning. In: Michaelsen L Team-Based Learning: A Transformative Use of Small Groups. Praeger Publisher, Westport, pp. 27-51.

Nevo, I. and Slonim-Nevo, V. 2011. The myth of evidence-based practice: Towards evidence-informed practice. British Journal of Social Work 41(6), 1176-1197. Nieder, G., Parmelee, D., Stolfi, A., Hudes, P. 2005. Team-based learning in a medical gross anatomy and embryology course. Clinical Anatomy 18, 56-63. Nursing \& Midwifery Council, 2010. Standards for Pre-Registration Nursing Education. Nursing \& Midwifery Council, London.

Parmelee, D., Michaelsen, L. 2010. Twelve tips for doing effective Team-Based Learning (TBL). Medical Teacher 32, 118-122. 
Parmelee, D., Michaelsen, L., Cook, S., Hudes, P. 2012. Team-based learning: A practical guide: AMEE Guide No. 65. Medical Teacher 34, e275-e287.

Pelley, J., McMahon, K. 2008. Facilitator skills. In Michaelsen L, Parmelee D, McMahon K, Levine R e ds. Team-Based Learning for Health Professions Education: A Guide to Using Small Groups for Improving Learning. Stylus Publishing, Virginia, pp. 99-102. Ratta, C. 2015. Flipping the classroom with team-based learning in undergraduate nursing education. Nurse Educator 40(2), 71-74.

Sibley, J., Parmelee, D. 2008. Knowledge is no longer enough: Enhancing professional education with team-based learning. New Directions for Teaching and Learning 116, 41-53.

Stevens, M. (2013) The impact of evidence-based practice in nursing and the next big ideas. The Online Journal of Issues in Nursing 18(2), Manuscript 4.

Sweet, M., Michaelsen, L. 2012. Critical thinking and engagement. Creating cognitive apprenticeships with team-based learning. In Sweet M, Michaelsen L eds. TeamBased Learning in the Social Sciences and Humanities. Stylus Publishing, Virginia, pp. 5-32.

Tan, N., Kandiah, N., Chan, Y., Umapathi, T., Lee, S., Tan, K. 2011. A controlled study of team-based learning for undergraduate clinical neurology education. BMC Medical Education 11, 91.

Thompson, B., Levine, R., Kennedy, F. et al 2009. Evaluating the quality of learningteam processes in medical education: Development and validation of a new measure. Academic Medicine 84(10), S124-S127.

Vasan, N., DeFouw, D., Compton, S. 2009. A survey of student perceptions of team based learning in anatomy curriculum: Favorable views unrelated to grades. Anat Sci Educ 2, 150-155. 
Zgheib, N., Simaan, J., Sabra, R. 2011. Using team-based learning to teach clinical pharmacology in medical school: Student satisfaction and improved performance. The Journal of Clinical Pharmacology 51, 1101-1111. 
Table 1: Perceptions of Team-Based Learning

\begin{tabular}{lllll}
\hline Subscale & $\mathbf{n}$ & Mean & SD & 95\% C.I. \\
\hline $\begin{array}{l}\text { Perception of team- } \\
\text { based learning }\end{array}$ & 190 & 2.43 & 4.97 & $1.71,3.14$ \\
$\begin{array}{l}\text { Perception of } \\
\text { teamwork }\end{array}$ & 188 & 9.59 & 3.23 & $9.12,10.05$ \\
\hline
\end{tabular}


Table 2: Attitudes to Team-Based Learning (\%)

\begin{tabular}{llllll}
\hline Statement & $\begin{array}{l}\text { Strongly } \\
\text { Agree }\end{array}$ & Agree & Uncertain & Disagree & $\begin{array}{l}\text { Strongly } \\
\text { Disagree }\end{array}$ \\
\hline $\begin{array}{l}\text { TBL approach was } \\
\text { appropriate for this } \\
\text { module }(n=196)\end{array}$ & $50(25.5)$ & $83(42.3)$ & $49(25.0)$ & $10(5.1)$ & $4(2.0)$ \\
$\begin{array}{l}\text { I did not think iRATs } \\
\text { were useful learning } \\
\text { activities ( } n=196)\end{array}$ & $20(10.2)$ & $43(21.9)$ & $51(26.0)$ & $71(36.2)$ & $11(5.6)$ \\
$\begin{array}{l}\text { I learn better from } \\
\text { lecture presentations } \\
\text { than in team work } \\
\text { ( } n=195)\end{array}$ & $38(19.4)$ & $40(20.4)$ & $61(31.1)$ & $44(22.4)$ & $12(6.1)$ \\
$\begin{array}{l}\text { Overall I did not } \\
\text { enjoy the TBL } \\
\text { approach ( } n=196)\end{array}$ & $26(13.3)$ & $32(16.3)$ & $44(22.4)$ & $64(32.7)$ & $30(15.3)$ \\
$\begin{array}{l}\text { TBL is an effective, } \\
\text { motivating learning } \\
\text { strategy }(n=195)\end{array}$ & $37(18.9)$ & $82(41.8)$ & $53(27.0)$ & $15(7.7)$ & $8(4.1)$ \\
$\begin{array}{l}\text { I recommend using } \\
\text { the TBL approach in } \\
\text { future courses } \\
(n=196)\end{array}$ & $27(13.8)$ & $80(40.8)$ & $57(29.1)$ & $24(12.2)$ & $8(4.1)$ \\
\hline
\end{tabular}

